ARTIGO CIENTÍFICO

\title{
A TEORIA DO AUTO-CUIDADO E SUA APLICABILIDADE NO SISTEMA DE ALOJAMENTO CONJUNTO
}

\author{
Adriana Remor1, Ilza Schmidt de Brito1, Vitória Regina Petters1, Evanguelia K. A. cios Santos 2
} REMOR. A. et alii. A teoria do auto-cuidado e sua aplica-
bilidade no sistema de alojamento conjunto. Rev. Bras. Enf., Brasília, 39 (2/3): 6-11, abr./set. 1986.

\begin{abstract}
RESUMO. O trabalho se refere à aplicação da teoria do OREM no sistema de alojamento conjunto, visando determinar as deficiências das capacidades dos indivíduos para execução de medidas de auto-cuidado.
\end{abstract}

\begin{abstract}
This is a work about the application of OREM's Theory in the Rooming-in System, in order to determine the deficiencies of individual's capacities for execution of self-care measures.
\end{abstract}

\section{INTRODUÇÃO}

A Teoria do Auto-Cuidado de Dorothea Orem, publicada em 1971 e 1980, foi desenvolvida a partir de um marco conceitual no qual OREM ${ }^{3}$ acredita que o profissional de enfermagem juntamente com o cliente, deve identificar déficits de capacidade no atendimento das necessidades individuais de auto-cuidado, procurando desenvolver nestes indivíduos os potenciais já existentes para a prática do auto-cuidado. Desta forma, o profissional de Enfermagem funciona no auto-cuidado como regulador do sistema. Ele identifica os déficits de competência em relação à demanda de auto-cuidado, faz pelo indivíduo aquilo que ele não pode fazer, ensina, orienta e promove o desenvolvimento das capacidades do indivíduo para que ele possa se tornar independente da assistência de enfermagem assumindo seu auto-cuidado. Estas capacidades podem se desenvolver no dia a dia, através de um espontâneo processo de aprendizagem, auxiliado pela curiosidade intelectual, pela instrução e supervisão de outros ou pela experiência na execução de medidas de auto-cuidado (OREM 3 ).

Assim sendo, após pesquisas bibliográficas, optamos por utilizar como marco de referência a Teoria do Auto-Cuidado no Sistema Alojamento Conjunto (Rooming-in) que é definido como um sistema hospitalar em que o recém-nascido (R. N.) permanece ao lado da mãe desde o momento do parto até a alta da maternidade, possibilitando no mesmo espaço físico a prestação de todos os cuidados assistenciais e de orientação à mãe sobre a saúde do binômio mãe/filho.

\section{(ENCONTRO NACIONAL SOBRE ALOJAMENTO CONJUNTOl).}

O sistema em que foi desenvolvido o trabalho está localizado na Maternidade Carmela Dutra (MCD) da Fundação Hospitalar de Santa Catarina, em Florianópolis. Possui sete leitos/binômio destinados a receber puérperas e recém-nascidos considerados normais, física e mentalmente.

Acreditamos que a natureza materna vem se encarregando dos cuidados necessários para a manutenção da saúde do binômio sendo isto de ordem natural e não com base em orientações específicas.

Baseados nesta reflexão, procuramos estimular os instintos maternos nas mães já habituadas a receberem pronto atendimento dos profissionais um tanto quanto paternalistas. Ainda nos questionamos o porquê de não estimularmos estes instintos, já um pouco adormecidos, colocando em prática a Teoria do Auto-Cuidado de Orem, quando então atuaríamos orientando e identificando a capacidade das puérperas para o auto-cuidado.

O presente trabalho foi desenvolvido no período de $02 / 01 / 85$ a $04 / 02 / 85$ e teve como objetivos tecer consideraçōes de natureza prática sobre a aplicabilidade desta teoria no Sistema Alojamento Conjunto, sem a pretensão de aplicarmos os aspectos teóricos na integra e tão profundamente como os profissionais que têm maior domínio nesta área.

Iniciaremos a apresentação do tema com a exposição do marco teórico da Teoria de Orem para

1. Formandas do Curso de Graduação em Enfermagem da Universidade Federal de Santa Catarina, Floria nópclis, SC,., Brasil.

2. Universidade Federal de Santa Catarina e Enfermeira da Matemidade Carmela Dutra, Fundação Hospitalar de Santa Catarina, Florianópolis, SC., Brasil. 
posteriormente discutirmos sua utilidade prática e avaliarmos sua eficiência, opinando sobre sua praticabilidade no Sistema Alojamento Conjunto.

\section{MARCO TEORICO}

NEWMAN 2 define marco teórico como a matriz de conceitos os quais, juntos, descrevem o foco de investigação. Para OREM ${ }^{3}$, o foco desta investigação é o homem, que é definido pela autora como uma unidade, funcionando biológica, simbólica e socialmente.

Um ser que está em íntima relação com o meio ambiente, que adapta suas necessidades aos estresses do meio, mas que utiliza tecnologia para controlá-las a fim de satisfazer suas necessidades.

O funcionamento do homem está ligado ao seu ambiente e juntos formam um todo integrado, funcional, isto é, um sistema. Os valores e normas sociais, os mecanismos fisiológicos e os padrões específicos de resposta do indivíduo aos estímulos ambientais afetarão o curso de ação selecionado e seguido pelo indivíduo.

A enfermagem tem como principal preocupação a necessidade do indivíduo de auto-cuidar-se e a provisão e manutenção deste auto-cuidado de uma forma contínua, de modo a manter a vida e a saúde, recuperar a doença ou dano e enfrentar seus efeitos $\left(\mathrm{OREM}^{3}\right)$.

A condição que justifica a existência da enfermagem para o indivíduo adulto é a ausência da capacidade de manter continuarnente aquela quantidade e qualidade de auto-cuidado que é terapêutica na manutenção da vida e da saúde, na recuperação, após a doença ou dano, ou a maneira de enfrentar seus efeitos. Para a criança, a condição de existência da enfermagem é relacionada à inabilidade dos pais e responsáveis em manter continuamente para ela aquela quantidade e qualidade de cuidado terapêutico necessário.

OREM 3,4 define auto-cuidado como ". . . a prática de atividades que indivíduos pessoalmente iniciam e desempenham em seu próprio benefício para manter a vida, saúde e bem-estar."

Há três tipos de auto-cuidado: o universal, o de desenvolvimento e o de desvios de saúde.

As necessidades de auto-cuidado universal são descritas como atividades da rotina diária ou aquelas que vão de encontro às necessidades humanas básicas.

O auto-cuidado necessário para o desenvolvimento ocorre durante determinado estágio de desenvolvimento, ou são derivadas de uma condição (por exemplo gestação), ou são associado com um evento (por exemplo, o nascimento de um bebê).

As necessidades de auto-cuidado relativas aos desvios da saúde só são sentidas pelos indivíduos na presença de doenças ou em certas situações especiais.

$\mathrm{O}$ marco conceitual da Teoria de auto-cuidado inclui três conceitos básicos: a) self care agency - é o poder, competência ou potencial dos indivíduos para se engajarem no auto-cuidado de forma a atender suas necessidades individuais para a manutenção da vida, saúde e bem estar; b) therapeutic self care demande - refere-se à totalidade das ações de auto-cuidado a serem desempenhadas, pelos indivíduos para a manutenção da vida, saúde e bem estar; c) nursing agency - refere-se à capacidade ou potencial dos profissionais de enfermagem para desempenhar ações de autocuidado para, pelo e com o indivíduo $\left(\mathrm{OREM}^{3}, 4\right)$.

A teoria consta também de outros conceitos básicos que auxiliam nosso entendimento quando procuramos direcioná-la para a prática. São eles:

- Saúde é um estado de totalidade ou integridade do ser humano individual, suas partes e seus modos de funcionamento.

- Déficits do Auto-Cuidado: foco da enfermagem e critérios para identificar quem, quando e porque enfermagem é necessária.

- Ações de Auto-Cuidado: porque as ações são necessárias para continuação da vida.

- Sistemas de enfermagem são o produto da prática da enfermagem e é através deles que o agency (competência, poder, capacidade) dos indivíduos em auto-cuidar-se é regulado. Explica como as pessoas podem ser ajudadas pela Enfermagem.

OREM $^{3}$ estabelece três tipos de sistemas de enfermagem relacionados com a dinâmica do autocuidado. Estes sistemas se referem como determinar os déficits dos indivíduos para atendimento da demanda terapêutica de auto-cuidado, necessária à manutenção de saúde e bem-estar. São eles: sistema de compensação total, sistema de compensação parcial e sistema de suporte educativo.

O sistema de compensação total é utilizado quando o indivíduo está totalmente incapacitado para atender a suas necessidades de auto-cuidado. O sistema de compensação parcial é aplicado quando o cliente apresenta algumas dificuldades de competência para atender a suas necessidades de auto-cuidado. Neste sistema, o indivíduo atende a uma parte de suas necessidades, mas não consegue atender à totalidade da demanda terapêtica de auto-cuidado. O sistema de suporte educativo é aplicado quando o cliente necessita da assistência de enfermagem para adquirir conhecimento e habilidades, poder decisório e comportamento de controle em relação às suas necessidades de auto-cuidado. Segundo OREM ${ }^{3}, 4$, a determinação de sistemas de assistência de enfermagem relacionados ao auto-cuidado indicam que espécie de métodos o profissional de enfermagem deve utilizar, para instituir e manter a assistência ao cliente. Entretanto, os objetivos da assistência relacionados a quaisquer dos sistemas já citados deverão ser desenvolvidos de forma a ajudar os clientes na seleção, planejamento e execução das medidas de auto-cuidado, necessárias à manutenção, restauração da saúde e convivência com os efeitos e limitações da própria doença.

$\mathrm{O}$ inter-relacionamento dos conceitos de OREM 3 , 4 são os elementos que constituem sua teoria. Segundo a autora, o relacionamento destes conceitos pode ser assim representado: 


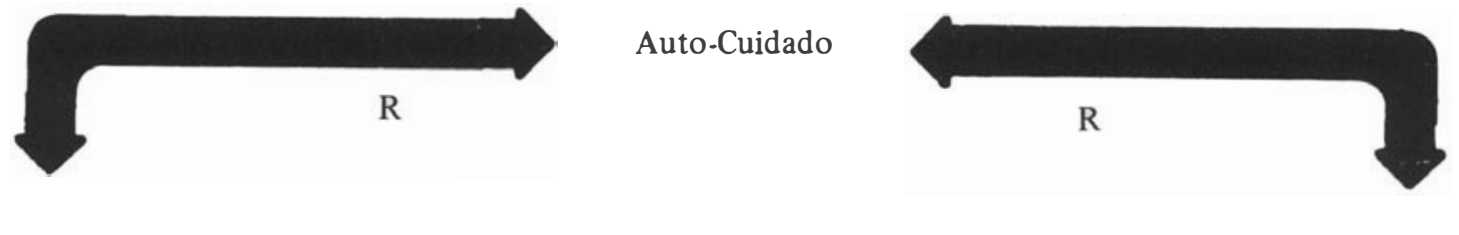

Competência dos indivíduos para autocuidado

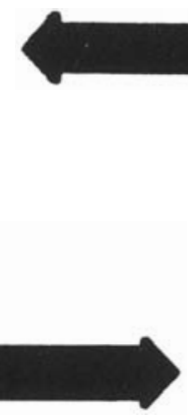

$\mathrm{R}$

\begin{abstract}
2
Competência de enfermagem para o auto-cuidado
\end{abstract}

Demanda terapêutica de auto-cuidado

FIGURA 1 - Adaptação do relacionamento dos conceitos de OREM 4 .

Quando ocorrer uma deficiência na competência dos indivíduos para o auto-cuidado em relação à demanda terapêtica do auto-cuidado, aí então se estabelecerá a necessidade da intervenção da enfermagem.

\section{OBJETIVOS}

Objetivo Geral: Determinar as deficiências de capacidades dos indivíduos, para execução das medidas de auto-cuidado - necessárias à manutenção da saúde e bemestar e, a partir deste referencial, classificar os indivíduos nos sistemas de enfermagem. A seguir, conforme estas determinações, devemos colocar em prática as ações de enfermagem necessárias, segundo OREM 3,4 .

Objetivos Especificos:

- Identificar o poder de agenciar de cada puérpera.

- Classificar as puérperas de acordo com os três sistemas de enfermagem citados por Orem.

- Elaborar um plano de ação de enfermagem, de acordo com as necessidades de cada puérpera, distribuindo os cuidados de enfermagem.

- Iniciar, conduzir e controlar as ações de enfermagem necessárias para o auto-cuidado, relacionados com os cuidados puerperais: higiene corporal, loqueação, involução uterina, aleitamento materno, terapêutica e cuidados com os recém-nascidos.

- Capacitar as puérperas no seu auto-cuidado e com o R. N., para que esteja habilitada a manter e dar continuidade às ações para a manutenção de saúde do binômio.

\section{O PROCESSO DE ENFERMAGEM}

A fundamentação teórica do processo de enfermagem, segundo OREM ${ }^{4}$, é a de que as ações devem estar em consonância com os objetivos desejados; de- vem tomar em conta os fatores ambientais, tecnológicos e humanos para a obtenção dos objetivos; devem ser desempenhadas de acordo com o planejamento, mas devem ser feitas as revisões e adaptações no planejamento à medida que as condições mudem; $\mathrm{e}$, por fim, devem ser controladas para verificar se os objetivos estão ou não sendo atingidos. Seus componentes incluem duas fases: uma intelectual e outra prática. $\mathrm{Na}$ fase intelectual, deve-se: a) determinar por que a pessoa precisa da enfermagem, considerando a história da vida do paciente e seu estilo de vida; b) determinar como a pessoa pode ser ajudada pela enfermagem, ou seja, projetar um sistema de enfermagem que efetivamente contribua para a obtenção dos objetivos de saúde do indivíduo; c) planejar a assistência incluindo especificação dos papéis (do indivíduo e da enfermagem), recursos, coordenação de atividades em termos de tempo, lugar e freqüência.

$\mathrm{Na}$ fase prática, deve-se iniciar, conduzir e controlar as ações de auto-cuidado.

Entendemos que a fase intelectual constitui a parte principal do processo, na qual o enfermeiro em contato com o paciente irá conhecer as ações de autocuidado que fazem parte de sua vida, bem como a validade destas ações, suas crenças e tabus com relação a cada etapa de seu desenvolvimento e, em especial, a esta fase do ciclo biológico vital que inclui duas situações importantes, como o nascimento e a reprodução.

A fase prática se constitui na continuidade da fase anterior, uma vez que nos possibilita determinar o déficit do seu auto-cuidado e planejar a demanda terapêutica.

- Roteiro de Dados de Base segundo OREM 3,4 , Baseado nas Necessidades do Binômio Mãe/Filho.

$\mathrm{O}$ roteiro dos dados de base foram elaborados a partir de um questionário (V. Anexo I) que nos permitiu a determinação da capacidade da puérpera de auto-cuidar-se e estender o mesmo ao seu Recém-Nas- 
cido. Associado a este questionário, elaboramos alguns itens que foram observados no decorrer de sua aplicação, que também nos auxiliou na determinação do agency. Englobamos a avaliação das capacidades físicas, mentais, motivacionais e emocionais nestes questionamentos.

$\mathrm{O}$ questionamento enfermeiro-paciente foi conduzido de maneira informal, sendo que o diálogo com as mães foi dirigido pelas perguntas pré-elaboradas, não se ficando, porém, a elas, restrito.

Ressaltamos que não foi nossa preocupação obter respostas a todas as perguntas constantes do roteiro como também nem sempre abordamos o assunto na forma e ordem dele constantes.

\section{RESULTADOS E COMENTARIOS}

Durante a nossá permanência (2 de janeiro a 4 de fevereiro de 1985), foram internadas oitenta e uma puérperas e, destas, sessenta e seis receberam assistência de enfermagem planejada e individualizada, através do processo de enfermagem baseado na Teoria de OREM 3,4 .

Esclarecemos, aqui, que as puérperas que tinham alta na segunda-feira e as que internavam sextafeira depois das 15:00 horas eram orientadas apenas quanto ao auto-cuidado, pois seria impossível dar continuidade aos processos tendo em vista que não poderíamos fazer um controle de suas atividades como previsto.

\section{Objetivos Previstos e Alcançados}

- Identificar o poder de agenciar (self care agency) de cada puérpera.

Para determinar a capacidade da puérpera em auto-cuidar-se, e estender o mesmo a seu recém-nascido, utilizamos um formulário e relatamos alguns dos itens já estabelecidos, o que nos permitiu avaliar mais precisamente as capacidades físicas, mentais, motivacionais e emocionais.

De acordo com o previsto, a aplicação do formulário e o relato das observações foram realizados de uma maneira bastante informal, colocando a paciente bem à vontade para fazer suas colocações e questionamentos, sendo que aplicávamos o processo aproveitando as oportunidades que nos propiciavam maior receptividade por parte das puérperas, ou seja, normalmente durante a chegada da mãe e do recémnascido à unidade, para verificação dos sinais vitais, curativo perineal, etc.

À medida que fomos aplicando o formulário, sentimos a necessidade de alterá-lo com relação a duas perguntas, visto que a grande maioria das puérperas não tinha conhecimentos da anatomia de seus órgãos e suas capacidades de observação não eram tão aguçadas. São elas: "Como você se sente após ter tido o bebê"? e "Quais as mudanças que a senhora percebe com relação ao seu corpo após o nascimento do recém-nascido?"

Conforme haviâmos planejado, cada acadêmica de enfermagem se responsabilizou por duas puérperas, no entanto, mantinha-se ciente da evolução das demais pacientes, através da leitura do processo de enfermagem e transmissão verbal.
- Classificar as puérperas de acordo com os três sistemas de enfermagem citados por $\mathrm{OREM}^{3}, 4$.

Após aplicação do questionário e relato das observações, as puérperas eram classificadas nos três sistemas de enfermagem relacionados com a dinâmica do auto-cuidado, citados por Orem. Dos 66 processos realizados com as pacientes, 95,5\% foram enquadrados no sistema suporte educativo e $4,5 \%$, no sistema de compensação parcial.

- Elaborar um plano de ação de enfermagem, de acordo com as necessidades de cada puérpera, distribuindo os cuidados de enfermagem.

Depois de levantarmos as necessidades das puérperas e o self care agency, elaborávamos a demanda de acordo com o déficit apresentado. A seguir iniciavámos, conduzíamos e controlávamos estas ações de enfermagem ṇecessárias para o auto-cuidado.

Inicialmente, foi estabelecida uma demanda terapêutica básica, onde estavam englobadas as orientações mais freqüentes (Vide Anexo 1). À medida que eram detectados novos déficts, o plano de assistência era complementado.

A demanda terapêtica contida no processo de enfermagem era transcrita para o prontuário da paciente, propiciando assim um maior número de informações registradas e favorecendo maior intercâmbio multiprofissional.

Acreditamos, ainda, que $100 \%$ das puérperas saíram do sistema de alojamento conjunto habilitadas a manter e dar continuidade no seu auto-cuidado e com o recém-nascido, mantendo assim a saúde do binômio.

\section{Objetivos não Previstos e Alcançados}

- Estimular banho de sol e extração manual de leite.

Conforme diretrizes estabelecidas no nosso planejamento com relação ao aleitamento materno, não tínhamos programado levar as puérperas ao sol.

Baseados nas orientações de VINHA 5 , na rotina existente na MCD e na nossa conscientização de sua importância, decidimos utilizar 15 minutos de cada manhã para levar as puérperas ao sol, onde eram orientadas sobre profilaxia e tratamento de fissuras mamilares, engurgitamento mamário, outros problemas práticos de amamentação e ainda sobre a técnica de extração manual do leite.

E importante salientar que das oitenta e uma puérperas que foram orientadas na unidade VIII (Sistema de Alojamento Conjunto) apenas uma paciente retornou à maternidade com problema de engurgitamento mamário, comprovando na prática a eficiência da metodologia aplicada.

- Participar na passagem de plantão.

Não tínhamos previsto participar da passagem de plantão conforme rotina da instituição, no entanto a acadêmica de enfermagem que cumpria horário das 15:00 às 19:00 horas ficava responsável pela transmissão de ocorrências de cada paciente, visto que permanecíamos 12 horas prestando assistência contínua ao binômio mãe/recém-nascido (das 07:00 às 19:00 horas). 
- Administrar medicamentos.

- Verificar sinais vitais.

Não determinamos, no planejamento, como seria viabilizada a administração dos medicamentos $\mathrm{e}$ verificação dos sinais vitais. De acordo com o nível de escolaridade e de auto-determinação, as puérperas eram orientadas quanto ao nome da medicação, dosagem, via de administração e finalidade, possibilitando assim que a própria paciente realizasse sua terapêutica. Os remédios ficavam dispostos sobre uma estante e elas próprias se auto-medicavam com a nossa supervisão, exceto as que tinham como via de administração intramuscular. Com relação aos sinais vitais, nós verificávamos às 08:00 horas e 14:00 horas.

- Orientar sobre higiene corporal e curativo perineal

Pela manhã, as pacientes eram orientadas e auxiliadas quanto à higiene corporal e curativo perineal (rotina). Além disso, eram informadas onde poderiam encontrar curativos perineais, lençóis e iodo aquoso necessários para realização de seu auto-cuidado. A partir desses procedimentos, as puérperas realizavam seu curativo perineal, troca de lençóis e forrinhos, contando somente com o nosso controle. Apesar das puérperas realizarem estas atividades, adotamos como rotina exame físico (mamas, involução uterina, lóquios, episiorrafia) no período matutino e vespertino, dando condições para uma avaliação do estado geral. Durante nossa permanência no sistema de alojamento conjunto, constatamos que realmente se trata do melhor local para o aprendizado e início de auto-cuidado da mãe e do recém-nascido. Suas vantagens são inúmeras.

Verificamos também que normalmente as multíparas questionavam quanto à permanência do recém-nascido no primeiro dia, pois estavam bastante "cansadas e com sono atrasado". Apesar de serem multíparas, a grande maioria necessitava de orientações com relação aos cuidados puerperais: in tegridade cutâneo-mucosa, eliminações, lóquios e terapêutica com o recém-nascido. Questionamos com relação às grandes multíparas, pois todas tinham receio quanto à higiene e realização de curativo do cordão umbilical do recém-nascido. Este fato nos levou a uma dúvida: seria em função do funcionamento do berçário central onde a mãe não lidava com o recém-nascido nos primeiros dias, nas internações anteriores?

Com relação ao aleitamento materno, percebemos que as grandes multíparas ou mesmo as primíparas já estavam mais conscientes da importância da amamentação. No entanto, muitas relataram que, em gestações anteriores, amamentaram somente nos primeiros dias, outras no 10 mês, alegando inúmeras razões como: "leite fraco, pouco leite, leite secava, seio caído, etc. . .", reforçando a necessidade de dar continuidade aos programas de incentivo ao aleitamento matemo.

Concordamos com ZIEGEL \& CRANLEY6 quando afirmam que o povo está aprendendo que embora a gravidez seja um processo natural, a natureza por si só, sem ajuda da ciência médica, não basta para fazer o corpo da mãe continuar funcionando normalmente nas situações de grande tensão. Em análise de sessenta e seis puérperas, foi verificado que $68,18 \%$ realizaram pré-natal e apenas 30,30\% não fizeram este acompanhamento médico. No entanto, constatamos que este atendimento não está satisfazendo totalmente às reais necessidades desta população, pois chegam no período de trabalho de parto e no puerperal cheias de dúvidas e questionamentos, quando ao nosso ver já deveriam ter alguma noção do que se passa com elas e que tipo de atitude deveriam assumir. Resta saber se o quem vem ocorrendo é em função da falta de assistência de enfermagem nesta área de atuação, ou se há falta de interesse médico e monopolização de seu saber? Ou se isto decorre, ainda, do baixo nível cultural dessa população que procura ser assistida. Examinando as sessenta e seis puérperas com processos de enfermagem em relação ao seu grau de escolaridade, observou-se que: $3,1 \%$ eram analfabetas, $33,4 \%$ possuíam primário, $45,4 \%$ o 19 grau, $15,1 \%$ o 2 o grau e, com grau superior, apenas $3,0 \%$. Verificamos que, embora as puérperas apresentassem algum grau de instrução, elas continuaram apresentando déficit com relação à saúde e educação sexual. Estes dados servem para reflexão da situação atual do ensino com relação à saúde, ou seja: será que o sistema está alerta?

Do total de sessenta e seis puérperas $44,0 \%$ eram primíparas, $22,0 \%$ secundíparas e $34,0 \%$ multíparas.

\section{CONCLUSÓES}

A Teoria do Auto-Cuidado de Dorothea Orem, utilizada como marco de referência para atuação no Sistema de Alojamento Conjunto, demonstrou ser eficiente por já fazer parte dos instintos humanos "o cuidar dos filhos", "o cuidar de si mesma", etc. faltando apenas uma abordagem organizada dos profissionais para estabelecer melhor essa relação.

Das sessenta e seis puérperas da população amostral, 95,5\% foram enquadradas no sistema de suporte educativo onde prevalece ram as orientações sobre os aspectos teóricos e práticos da amamentação, os cuidados gerais com o recém-nascido e os cuidados puerperais.

A aplicação de uma metodologia de assistência dirigida ao paciente, aguçou nossa percepção quanto à importância da mesma, pois, além de sistematizar nossa atuação, não só direcionando mas aperfeiçoando, beneficiou aquele que a recebeu.

A escolha e a utilização dos diversos marcos teóricos devem ser eleitas, quando na sua transposição para a prática, considerando-se a área de atuação.
REMOR, A. et alii. The Orem's theory and their applica- bility in the Rooming-in System. Rev. Bras. Enf., Brasilia, 39(2/3): 6-11, Apr./Sept., 1986.

REFE REENCIAS BIBLIOGRAFICAS

1. ENCONTRO NACIONAL SOBRE ALOJAMENTO CONJUNTO. Relatório final. Brasilia, Ministério da Saúde/INAN, 1982.

2. NEWMAN, M. Theory development in nursing. Philadelphia, F. A. Davis, 1979.

3. OREM, D. E. Nursing: concepts of practice. New York,

4. Mac Graw-Hill, 1971. 232p. 
5. VINHA, V. H. P. Amamentação materna; incentivo $e$ cuidados. São Paulo, Sarvier, 1983.

6. ZIEGEL, E. \& CRANLEY, M. S. Enfermagem obstétrica. 8. ed. Rio de Janeiro, Interamericana, 1985.

\section{ANEXO 1}

Desenvolvimento do Instrumento - Elaboração do questionário que nos auxiliará na determinação da capacidade da puérpera de auto-cuidar-se e estender o mesmo ao seu Recém-nascido. Englobamos uma avaliação das capacidades físicas, mentais, motivacionais e emocionais nestes questionamentos.

a) Como se sente após ter tido o bebê?

b) Quais as mudanças que percebeu em relação ao seu corpo, após o nascimento do bebê?

c) Já possuía informações de como seria o período puerperal - ("resguardo")? Se as recebeu, quais as fontes e qual o tipo de orientação dada?

d) Está decidida a amamentar seu bebê? Por que?

e) Já recebeu alguma orientação com relação à amamentação?

f) Já teve oportunidade de cuidar ou lidar com recém-nascidos?

g) O que sabe sobre os cuidados que devemos ter com o recém-nascido?

h) Sua gravidez foi planejada? Havia preferência com relação ao sexo do seu bebê (sua ou de seu esposo)?

i) Pretende dar todos os cuidados necessários ao seu bebê quando estiver em casa?
Pretendemos abordar estas perguntas de uma maneira bastante informal. Nosso diálogo com a puérpera será dirigido pelas perguntas pré-elaboradas, no entanto, não ficaremos restritas às mesmas. Logo após o diálogo, o mesmo será anotado no caderno, onde cada puérpera terá uma folha individual.

Associada a este questionário, elaboramos alguns itens que serão observados no decorrer da conversa, a qual também nos auxiliará na determinação do agency.

Itens que serão observados:

- Estado físico da puérpera e do R.N.

- Atividades e/ou procedimentos da puérpera com ela própria e com o seu R.N.

- Relacionamento da puérpera com as demais pacientes, bem como com os funcionários.

- Anotações do prontuário.

- Nível quantitativo e qualitativo dos questionamentos feitos pela puérpera e suas respostas frente às nossas perguntas.

Estes dois requisitos, que constam de relatos de paciente e impressão do entrevistador, serão transferidos para um caderno, onde cada paciente terá seu espaço. Após isso, serão avaliados para que se determine em qual sistema de enfermagem a paciente se enquadra, a partir dos déficits apresentados.

Acreditamos que, com estes dois requisitos, teremos dados suficientes para determinar, superficialmente, a capacidade que cada puérpera tem em autocuidar-se, e estender o mesmo ao seu bebê.

Decidimos que cada estagiária de enfermagem se responsabilizará em aplicar o processo de enfermagem segundo Dorothea Orem, em duas puérperas; no entanto, se encarregará de ler as anotações referentes às demais, bem como acrescentar observações e auxiliar no controle das mesmas, de acordo com a demanda terapêutica já estabelecida. 